\title{
(2) OPEN ACCESS \\ Reactions to electronic nicotine delivery system (ENDS) prevention messages: results from qualitative research used to inform FDA's first youth ENDS prevention campaign
}

\author{
Maria L Roditis ๑ ,'Atanaska Dineva, ${ }^{1}$ Alexandria Smith, ${ }^{1}$ Matthew Walker, ${ }^{1}$ \\ Janine Delahanty, ${ }^{1}$ Emily D'lorio, ${ }^{1}$ Kristen D Holtz ${ }^{2}$
}

${ }^{1}$ Office of Health

Communication and Education, Center for Tobacco Products, US Food and Drug Administration, Silver Spring, Maryland, USA ${ }^{2} \mathrm{KDH}$ Research and

Communication, Atlanta, Georgia, USA

\section{Correspondence to} Dr Maria L Roditis, Office of Health Communication and Education, Center for Tobacco Products, US Food and Drug Administration, Silver Spring, MD 20903, USA;

maria.roditis@fda.hhs.gov

Received 10 April 2019 Revised 31 July 2019

Accepted 6 August 2019 Published Online First 10 September 2019

\section{Check for updates}

(c) Author(s) (or their employer(s)) 2020. Re-use permitted under CC BY-NC. No commercial re-use. See rights and permissions. Published by BMJ.

To cite: Roditis $\mathrm{ML}$, Dineva A, Smith A, et al. Tob Control

2020:29:510-515.

\section{ABSTRACT}

Background Youth e-cigarette use is a major public health concern. Large-scale tobacco prevention campaigns are a proven strategy to prevent tobacco use. There is a gap in understanding what types of e-cigarette prevention messages might be most effective. This study addresses this gap by reporting youth reactions to health messages aimed at preventing e-cigarette use.

Methods In 2018, twenty-four focus groups, with 159 teens (12-17) at risk for or experimenting with e-cigarettes were conducted in four cities across the USA. During focus groups, youth responded to creative concepts dealing with (1) the addictive nature of ecigarettes, (2) the fact that e-cigarettes come in flavours, which may encourage youth initiation, and nicotine which may lead to addiction, or (3) that youth who use e-cigarettes are more likely to use cigarettes. Youth also gave feedback to specific facts about harmful and potentially harmful chemicals in e-cigarettes. Transcripts were analysed using thematic analysis.

Results Messages focusing on addiction alone did not resonate with participants. While youth found the idea that e-cigarettes may contain nicotine and can be addictive believable, with many describing personal experiences of addiction, they questioned how bad this really was, comparing addiction to e-cigarettes to things like being addicted to food. Participants wanted more information about negative consequences of vaping. Concepts paired with strong health effects messages resonated with participants.

Conclusion These focus groups clarified which ecigarette prevention messages might be most persuasive to teens. Youth in this study responded favourably to messages stating specific health consequences of ecigarette use.

\section{INTRODUCTION}

Electronic cigarette (e-cigarette) use among youth is a public health concern. E-cigarettes have replaced cigarettes as the most commonly used tobacco product among youth. ${ }^{1}$ Additionally, recent data from the National Youth Tobacco Survey show that, between 2017 and 2018, current use of e-cigarettes increased from $11.7 \%$ to $20.8 \%$ among high school students and from $3.3 \%$ to $4.9 \%$ among middle school students. ${ }^{2}$ In contrast to cigarettes, youth are generally less informed and knowledgeable about the dangers of e-cigarettes, in part because public health information is still emerging.
One proven strategy to prevent use of cigarettes among youth is mass media health prevention messaging campaigns. ${ }^{3-9}$ Because of previous tobacco education campaigns, and because the body of evidence on harms of smoking cigarettes has had decades to grow and be shared, the public is better informed about the harms of cigarette use. ${ }^{10}{ }^{11} \mathrm{In}$ contrast, the body of evidence on risks of e-cigarettes is in its infancy and the picture is more complicated. While e-cigarettes typically contain harmful and potentially harmful chemicals (HPHC) such as acrolein, diacetyl and formaldehyde, ${ }^{12-14}$ there is also a potential public health interest in e-cigarettes as an alternative for adult-addicted cigarette smokers to satisfy nicotine cravings while being exposed to fewer harmful chemicals. ${ }^{15}$ However, there is growing concern about the risks of e-cigarette use among youth as e-cigarettes can contain nicotine and the adolescent brain is particularly vulnerable to nicotine addiction. ${ }^{16}$ Multiple studies have also shown that use of e-cigarettes is associated with a greater likelihood of trying cigarettes in the future. ${ }^{17}$ There is also concern that the advent of new technologies allowing for more nicotine to enter the body faster, ${ }^{18}$ and the use of flavours such as candy and fruit flavours may be enticing youth to initiate electronic nicotine delivery system (ENDS) use among those not previously at risk of smoking. ${ }^{19-22}$ These factors have contributed to what US Department of Health and Human Services Secretary Alex Azar described as 'An epidemic of youth e-cigarette use, which threatens to engulf a new generation in nicotine addiction. ${ }^{23}$

Health messaging campaigns aimed at preventing e-cigarette use among youth thus have several special considerations, including (1) the body of evidence about possible harms related to use is still emerging, and (2) there is little guidance regarding what types of youth-focused e-cigarette prevention messages will be successful. There is a small body of emerging literature on what types of strategies may be effective for messaging on e-cigarettes. ${ }^{2425}$ Additionally, there is a dearth of literature assessing how youth respond to developed e-cigarette prevention messages.

This study reports on youth feedback to creative concepts (draft advertising in the form of illustrated storyboards with narration) and strategic concepts (messages that could be used in future advertising, delivered in the form of spoken statements) aimed 
at preventing youth e-cigarette use for 'The Real Cost' campaign. 'The Real Cost,' a national public education campaign focused on preventing tobacco use among youth aged 12-17, was launched in 2014 by the Food and Drug Administration (FDA).

\section{METHODS}

\section{Procedures and sample}

Participants were recruited using a pre-existing respondent database and screened for eligibility by telephone. Inclusion criteria included being between the ages of 12 and 17 and reporting being either susceptible to e-cigarette use, defined using Pierce's susceptibility scale, ${ }^{26}$ being an e-cigarette experimenter (had between 1 and 49 puffs of an e-cigarette ever, but used fewer than 21 e-cigarettes in the past 30 days) or being a dual e-cigarette and cigarette experimenter (for cigarettes, experimenter was defined as having had at least one puff but less than 100 lifetime cigarettes). Parental permission and participant assent were collected prior to participation; and participants were given a gift card as a token of appreciation for their time. Data collection was conducted in partnership with FCB New York and approved by FDA's Institutional Review Board. Data collection took place in January and February 2018.

Focus groups were conducted as follows: using a semistructured guide, a professionally trained moderator presented participants with images of a variety of e-cigarettes and asked youth what words people their age used to describe the products and the act of using them, where youth used them, with whom they used and what they knew about the products. Youth were then asked to give feedback on creative and strategic concepts, such as what they thought the ads were about, what they liked and disliked about the ads and how believable the ads were. During the focus groups, participants filled out a worksheet prior to discussing each concept and after having seen all the concepts. These written components were given to participants to help spur conversation and mitigate the risks of group think by having participants reflect on the ad prior to talking as a group. Analysis of these materials is outside the scope of this paper. All focus groups reviewed both creative and strategic concepts.

Creative concepts messaged on (1) the addictive nature of e-cigarettes, specifically that using e-cigarettes can result in a loss of control, (2) that e-cigarette flavours may entice youth to try them, but contain nicotine which is addictive, or (3) that youth who use e-cigarettes are more likely to use cigarettes (see box 1). Finally, youth were asked to give feedback on strategic concepts, which focused on specific facts about the HPHCs found in e-cigarettes. During the process of conducting the focus groups two changes took places: (1) youth consistently asked for more information about the harms of e-cigarette use, so halfway through the focus groups the statements on specific facts about the harms of e-cigarettes (strategic concepts) which were originally discussed at the end of the focus groups were shared immediately after certain creative concepts were shown, and (2) it became clear that youth were having difficulty comprehending the flavours concepts. Because of this, the narration of the main message of the creative concepts dealing with flavours was modified for clarity.

\section{Participants}

A total of 159 youth aged 12-17 participated in 24 focus groups across the major regions of the USA (Northeast, South, Midwest and Southwest). Participants were evenly split between males and females and were racially and ethnically diverse with $64 \%$ White, 21\% Black, 9\% Hispanic, 3\% Asian and 2\% Other.
Box 1 Description of creative concepts and strategic concepts

Concept category 1: The addictive nature of e-cigarettes, specifically the fact that using e-cigarettes can result in a loss of control due to addiction.

Epidemic: This ad uses a visual metaphor of a creature to represent the nicotine in e-cigarettes. It shows the creature travelling from the mouth after inhale, up under the skin in the face and burrowing into the brain. It then delivers the fact 'if you vape, you may be infected by nicotine, which can lead to a disease called addiction.'

Obey: This ad uses the metaphor of a dystopian world where a controlling force dictates teens' behaviour. We learn that this controlling force actually represents a nicotine addiction, and teens are forced to vape whenever they are told to. The ad ends with the fact 'Nicotine cravings are oppressive, and they may start with vaping.'

Nikki T: This ad uses the metaphor of bothersome phone notifications from 'Nicky $T^{\prime}$ to convey how nicotine cravings can disrupt your day. After seeing a teen bothered by the notifications while he is trying to study, play basketball and hang with his friends, the ad explains 'Nicotine is like a needy friend. If you vape, it may not leave you alone.'

\section{Concept category 2: The fact that the flavours in e-} cigarettes may lure you in, and then the nicotine addicts you.

Flavor of Addiction: This ad shows teens eagerly entering a candy factory. After eating the sweets, the candy starts to rot, and the factory gate locks behind them. As they are confused and worried, the ad explains 'Vape flavors can suck you in, but nicotine makes it hard to get out.'

Candy House: This ad displays a house made entirely of candy, and a narrator explains that teenagers excitedly enter the house and try candy. However, we soon realise that the house is actually made of candy-coated teenagers, who have worried facial expressions and are stuck in the house. The narrator then states, 'Vape flavors can suck you in, but nicotine makes it hard to get out.'

\section{Concept category 3: The fact that youth who use e- cigarettes are more likely to try cigarettes} Magic: This ad begins with a magician who asks teens if they would like to try a magic trick. The teens are holding a vape. The magician takes the vape in their hand, and when they open their hand, they are holding a cigarette. The teens are confused and worried, and the magician explains that teens who vape are more likely to try cigarettes.

Strategic concept messages tested:

- What if I told you researchers say there is not enough medical science yet to know how vaping might affect a teen's health in the future?

- What if we told you researchers have found that vapes could contain diacetyl; when inhaled this can lead to irreversible obstructive lung disease, which would make it permanently hard to breathe?

- What if we told you researchers have found that vapes could contain formaldehyde and acrolein-some of the same toxic chemicals found in cigarette smoke? 


\section{Box 1 Continued}

- What if we told you researchers have found that vapes could contain microscopic metal particles like nickel, tin and lead that can be inhaled deep into the lungs?

- Research has shown that the liquids in vapes might leak out. E-liquids containing nicotine may be poisonous if swallowed or absorbed through the skin.

Approximately $43 \%$ of participants were susceptible to e-cigarette use, $40 \%$ of participants were e-cigarette experimenters and $17 \%$ were dual e-cigarette and cigarette experimenters. Groups were mixed gender but stratified by age and use status.

\section{Data analysis}

Focus groups were transcribed from audio recordings. Three of the main authors read the same two transcripts from which an initial codebook was created. Next, they read another set of transcripts and met again to modify the codebook. The authors then split the remaining transcripts and read them separately. They met at regular intervals to discuss coding and alter the codebook as necessary; discrepancies in coding were dealt with through discussion and coming to consensus. Data were analysed for main themes using an inductive, thematic analysis approach as outlined by Braun et al. ${ }^{27}$ Illustrative quotes provided below are followed by these descriptors: focus group number (FGX); use status descriptor of at risk for using e-cigarettes (At-risk), e-cigarette experimenter (Exp), or dual experimenters of both e-cigarettes and cigarettes (DExp); and age group of younger youth 12-14 years of age (12-14) or older youth 15-17 years of age (15-17).

\section{RESULTS}

\section{Vaping associations}

Youth were shown images of different types of e-cigarettes and asked what terms people their age would use to describe the products. Youth responded by naming specific brands such as JUUL, Fix, Smok and Suorin Air. They also referred to the products as vapes, electronic cigarettes, e-cigarettes, e-cigs and mods or box mods. The most common ways to talk about these products were JUUL or vapes, and participants stated that youth refer to using these products generally as vaping and, in the case of JUULs, as juuling; other less frequently cited terms included smoking or hitting air. Youth described a variety of places where these products were used; many of these places were in schoolusually the school bathroom or directly in the classroom. For example, one youth explained, 'People can't go throughout the day without vaping in the bathroom' (FG16 Exp 15-17). Youth also described using them in cars, at their homes, at concerts, parties and further explained that you could use e-cigarettes 'Literally everywhere. Even in a restaurant. You could be sitting down at a [restaurant] and there is probably someone vaping somewhere' (FG15 Exp 12-14).

\section{Reactions to concepts describing the addictive nature of ENDS (Epidemic, Obey and Nicki T)}

Initial reactions

Youth understood that the main message of these creative concepts was that using ENDS can be addictive. Participants were able to restate the main message of the ads, stating, 'That vaping is bad, and it can cause addiction,' and 'Nicotine causes addiction, so don't vape' (FG10 Exp 15-17). Overall youth responded most positively to the concepts with a serious or dark tone. For example, one youth stated 'It scares way more than the last ad... The whole premise of the parasite as... nicotine, is just really describing it' (FG2 At-risk 15-17). (See box 1).

Participants found depictions of relatable scenarios appealing (eg, sitting at home doing homework, getting text messages on one's phone, hanging out with friends at a party). However, youth did not see specific, short-term examples of consequences of addiction to e-cigarettes as realistic and were quick to note that, unlike cigarette smoking, e-cigarette use does not need to happen outside of indoor social situations and would not necessarily cause an interruption to everyday activities. For example:

It depends on the situation, the certain thing that you're doing. If you're at work or something and you step out to vape or smoke a cigarette, that's going to get in the way. But, if you're sitting on your couch watching TV, it kind of doesn't really get in the way.... (FG3 Exp 12-14)

In particular, youth thought leaving a party to use e-cigarettes was an unrealistic scenario due to the social nature of vaping for youth: 'I just don't think [this works] because you don't have to go outside to smoke' (FG10 Exp 15-17). Another youth similarly noted, 'You can vape and do your homework...you can pretty much vape wherever' (FG6 Exp 15-17).

\section{Participant reactions to main message: ENDS being addictive}

Some youth were sceptical about nicotine addiction, stating, for example, 'Some people don't get addicted easily...Depends on if you are easily addicted to something or not. I don't get easily addicted. I don't care if it's 24\% nic or $0 \%$. I just do it for stress' (FG15 Exp 12-14). Others, however, had first-hand experience that e-cigarettes are addictive,

My friend, he does it [uses e-cigarettes] a lot. His mom took it. He came to school. He was real-You could tell. He was like, 'I haven't been vaping in a while.' He was white. It affects him now. He's addicted. Without it, he's like, 'I don't know what to do.' (FG1 At-risk 12-14)

Despite agreeing that ENDS were addictive, youth questioned how bad addiction to e-cigarettes really was, for example, one youth noted: 'You can get addicted to things that aren't bad. I guess addiction to anything isn't great, but you could get addicted to other things and it wouldn't be considered bad' (FG15 Exp 12-14). Youth brought up fast food, technology and other relatively less harmful things as examples of 'addictions' they did not consider to be bad, for example, stating:

They just said it can be addictive, but they didn't really give any reasons why that was bad. Some people might see that and be like, 'Well, it's addictive, but will it hurt me if it's addictive?' Like, hamburgers are addictive, will they hurt you...? (FG3 Exp 12-14)

Some youth also failed to see the harm in becoming addicted to e-cigarettes if the addiction did not lead to other health consequences. For example, one youth stated: 'I heard that it still got nicotine, which is addictive, ... but nobody has died from vaping, though. It's way better than cigarettes, I know that' (FG6 Exp 15-17). Participants did not feel that the message of addiction, on its own, provided them with a reason not to use e-cigarettes: 'I liked [the concept], but what can [vaping] do besides just making you addicted to something. It doesn't really show you what addiction can do, just says that you can get it' (FG2 At-risk 15-17). 


\section{Reactions to concepts describing flavours which may entice youth to try ENDS and then become addicted to nicotine (Flavor of Addiction, Candy House) \\ Initial reactions}

Overall, youth had difficulty understanding the main message of these ads. While many youth understood that the concepts were trying to portray the negative effects of using e-cigarettes, they also had difficulty understanding the reason for the candy images in the ads. Some youth, for example, thought the main reason for using candy was because youth like candy or to compare the allure of candy with the addictiveness of e-cigarettes, stating things like:

\begin{abstract}
I know a lot of people have [a] sweet tooth, like they really like sweets and that kind of stuff, so I think it kind of is like something that a lot of people can relate to. Because like, I like sugar. That kind of stuff. So, when you see that and then you relate it to that, I guess. (FG23 At-risk 12-14)
\end{abstract}

Due to early results indicating main message confusion, an in-field change was made midway through focus groups to make the main message of the ads more straightforward. Specifically, the narration changed from 'Vapes can contain nicotine, which is addictive. Once you get in, it may be hard to get out' for concept 1 and 'Think vaping is sweet? Think again. Its flavors may hide nicotine, which can make it addictive, like cigarettes' for concept 2, to the simpler 'Vape flavors can suck you in, but nicotine makes it hard to get out' for both concepts. After this change, some youth were able to restate the main message of the ads; however, overall youth still had difficulty understanding the main message of the ads. (See box 1).

\section{Participant reactions to main message: flavours luring youth into nicotine addiction}

When probed, some participants said that flavours were not a major reason why they used e-cigarettes and pointed to other things like peer pressure instead stating things like: 'I feel like it's more peer pressure. Like if you are going to vape, then you would do it without the flavor or not' (FG23 At-risk 12-14). There were also youth who stated that flavours were an important reason for why youth used: 'Because I know a lot of people that didn't vape and then they started vaping because of the flavors and now they vape also' (FG8 At Risk 15-17). Additionally, some participants felt that the candy and desert flavours depicted in the ads were not relatable, stating: 'I hear more about fruity flavors. I've never heard of cinnamon bun. It if were like strawberry, that would click better with me' (FG8 At-risk 15-17).

\section{Reactions across the addiction and flavour concepts}

Across the addiction and flavour concepts youth consistently asked for more information about the harms of using e-cigarettes. For example, participants stated: 'If you say something's addictive, you also have to say why being addicted to it is bad' (FG3 Exp 12-14), and 'They say they don't know all the health effects, and it's yet to be uncovered, but I wonder what more there is? (FG6 DExp 15-17), and 'I feel like if they focused more on what the long-term effects could be and really emphasized that, that would help stop vaping' (FG8 At-risk 5-17). Another participant asking for more information started filling in this lack of information with her own thoughts, stating:

I feel like if there was more research-because this is a very new thing-if the commercial came out and said, 'Vaping is directly related to lung cancer,' which I think it also is, 'and female infertility after the age of 20 '- I don't even know. If there were more facts about certain hazards that come along with this, which there already are, I think that if they talk more about that, that would be even more alarming. (FG10 Exp 15-17)

Participants' desire for specific health messages beyond addiction led to a decision midway through focus groups to move the strategic concepts section of the focus group discussion, where specific health consequences were discussed, from the end of the focus groups and ask about these specific health consequence messages while the creative concepts were being shown.

For example:

Moderator: Last thing before I show you the next one. I have a couple other facts that they could use... what if instead of this organism representing nicotine, the ad talked about how vapes could contain diacetyl, which when inhaled can lead to irreversible obstructive lung disease which could make it permanently hard to breathe?

Participant: I think that they could go with that or both because mentioning addiction, while like effective, if you know nothing about vaping, you just see this, and you're like, 'Well, why shouldn't I get addicted? That's dumb. I'll do what I want.' It's like just saying, 'Addiction is bad.' It's kind of like you'd need more of an argument than that, I guess.... I think that's more effective than nicotine.

Moderator: OK, why?

Participant: It says nicotine, they only talk about how could make you get addicted. But it's like, I forgot what it was called, but it makes it-it puts more detail on why you shouldn't do it....

Moderator: What if...the ad talked about how vapes could contain microscopic metal particles like nickel, tin and lead that can be inhaled deep into the lungs? Is that an effective message for this ad or not really?

Participant: I think that'd be effective.

Moderator: Why?

Participant: Because I don't think anyone would want that, and they'd be worried, so they'd make sure they wouldn't do it. (FG23 At-risk 12-14)

One of the strategic concepts shared explicitly messaged on the fact that the evidence for the risks of vaping is still emerging, with the statement, 'What if I told you that researchers say that there is not enough medical science yet to know how vaping might affect a teen's health in the future.' Reactions to this statement were mixed. Some youth felt this statement was alarming, for example, stating, 'Maybe it's worse [than cigarettes]...It makes me feel scared. I don't want to vape' (FG2 At-risk 15-17). Others felt that the statement condoned use, 'I feel like it's kind of on the pro side of vaping. I feel like it's not really saying that it's dangerous' (FG14 At-risk 12-14). Still others felt the statement could be interpreted multiple ways, 'It's like two sided, I feel like. It could be a good or bad thing' (FG14 At-risk 12-14).

\section{Reactions to the concept describing that youth who use ENDS are more likely to try cigarettes (Magic) \\ Initial reactions}

Overall, the main message of this concept was easily understood by participants. Youth responded favourably to the clear and specific information that the ad provided, for example, stating that they liked 'the fact that there are facts' (FG8 At-risk 15-17) and 'it's telling me that it's really happening, it's not fake.... believe it or not, it's true' (FG11 Exp 15-17). (See box 1).

Participant reactions to main message: youth who use ENDS are more likely to try cigarettes

Youth felt that relating using e-cigarettes back to cigarettes would be a deterrent to using e-cigarettes, for example, stating, 'I feel 
like you should stop vaping because I know what smoking causes to other people, so if it leads you to smoke, and smoking is obviously really bad for you. And if you know this one leads you to smoking, which smoking's bad, then why continue?' (FG12 DExp 15-17). Youth also were able to bring the main fact of this ad (that using e-cigarettes makes you more likely to try cigarettes) back to their own experiences, for example, stating, 'I can connect because this happened to one of my friends. She started vaping and now she does cigarettes' (FG11 Exp 15-17).

Some youth expressed doubt about the concept, for example, stating: 'If it was me, if they told me that I'm vaping and it's going to turn into a cigarette, I wouldn't necessarily believe them' (FG19 At-risk 12-17). Even some youth who had seen friends go from using e-cigarettes to smoking displayed scepticism about this concept, for example, stating: 'I don't totally believe that vaping could lead to cigarettes even though I've seen it firsthand because there are so many different types of juices that you can get them with no nicotine at all...' (FG11 Exp 15-17).

\section{DISCUSSION}

There is a lack of information regarding what types of prevention messages on the risks of e-cigarette use might be most effective. This study attempted to fill this gap by assessing how youth reacted to ads that focused on (1) the addictive nature of e-cigarettes, (2) flavours luring youth into nicotine addiction, and (3) the fact that youth who use e-cigarettes are more likely to use cigarettes, as well as specific facts about the HPHCs found in e-cigarettes.

A key finding from these groups was that messages focusing on addiction alone did not resonate with youth. These reactions differ from reactions youth have had to health messages focusing on the addictive nature of cigarettes-specifically the fact that cigarettes can result in a loss of control. Previous research from 'The Real Cost' campaign showed that youth responded favourably to ads that focused on real, short-term consequences of addiction to cigarettes. ${ }^{28}$ In this current study, while youth found the idea that e-cigarettes may contain nicotine and can lead to addiction believable, they questioned how bad being addicted to e-cigarettes really was, comparing addiction to e-cigarettes to being addicted to food and other relatively less harmful examples. Additionally, consequences like missing out on activities with friends did not resonate, as many youth felt that this was not a realistic consequence of vaping. There may be a few reasons why youth reacted differently to ads on cigarette addiction versus e-cigarette addiction. It is possible that, because youth already have heard so much information about the risks of smoking, when they see an ad focusing on cigarette addiction they are more easily able to infer why addiction to cigarettes is bad whereas with e-cigarettes that connection is less clear. Interestingly, past research with cigarettes shows that a major health messaging barrier is that youth tend to exhibit optimism bias and think they are less likely to be addicted to cigarettes than their peers. ${ }^{29} 30$ Results from this current research, however, suggest that youth may be more ready to accept that e-cigarettes are addictive, but the difficulty is in showing why this matters.

Similarly, youth did not respond well to ads that focused on flavours. Youth were confused about the main message, which may be because, while flavours are associated with youth use, ${ }^{20-22}$ youth themselves do not perceive of flavours as a reason why they decide to try e-cigarettes, or possibly because the flavours depicted were not reflective of what youth used. One important point to make is that the dissemination of a health effects message increases saliency and believability of the message. This allows for the possibility that if there were more messages about the fact the flavours entice youth to use e-cigarettes, this message might be more salient to youth which could, in turn, make this message easier to comprehend. These findings, however, highlight the fact that just because a health message is true does not mean it will resonate with the intended audience, and in these instances, it may be particularly important to also consider prevention approaches other than messaging.

The findings from these qualitative data, collected from a small group of respondents in only four US cities, are limited in their generalisability to the general population. Nonetheless, the findings reported below provide an important early look at promising e-cigarette prevention messages for youth.

\section{CONCLUSION}

The majority of youth in this study wanted more information about the negative consequences of using e-cigarettes, and concepts performed well when they were paired with a strong health effects message, such as the fact that using an e-cigarette can lead to trying cigarettes and e-cigarette vapour can expose the lungs to harmful chemicals such as acrolein. This study reinforces the idea that youth have little information about e-cigarettes and are looking for health effects messages with specific clear facts. This study also illustrates the unique challenges to messaging on the risks of using e-cigarettes, such as the fact that youth may not be concerned about addiction to e-cigarettes and that even true statements, such as the fact that we still do not know all the risks associated with using e-cigarettes, may be viewed as too ambiguous to be effective. As the scientific evidence regarding the risks of e-cigarette use continues to grow, more work will help researchers better understand what messages will be most effective at preventing e-cigarette use among youth.

\section{What this paper adds}

- While it is well known that large-scale health messaging campaigns are successful at reducing cigarette use among youth, there is little known regarding how youth will respond to health messages aimed at preventing e-cigarette use among youth. This study begins to address this gap by assessing youth reactions to a series of e-cigarette prevention messages.

Acknowledgements The authors thank and gratefully acknowledge the 'The Real Cost' campaign team at FDA, FCB New York, and KDH Research and Communication for producing the campaign and for collecting the data reported in this manuscript.

Contributors All authors helped in the conceptualisation, writing and editing of the paper. MLR, AD and AS did the analysis of the results. MLR led the writing of the manuscript.

Funding The authors have not declared a specific grant for this research from any funding agency in the public, commercial or not-for-profit sectors.

Disclaimer This publication represents the views of the author(s) and does not represent FDA/CTP position or policy.

Competing interests None declared.

Patient consent for publication Not required.

Ethics approval The FDA IRB reviewed and approved the protocol for this study (ID No 17-083CTP).

Provenance and peer review Not commissioned; externally peer reviewed. Data availability statement Data are available upon reasonable request.

Open access This is an open access article distributed in accordance with the Creative Commons Attribution Non Commercial (CC BY-NC 4.0) license, which permits others to distribute, remix, adapt, build upon this work non-commercially, and license their derivative works on different terms, provided the original work is 
properly cited, appropriate credit is given, any changes made indicated, and the use is non-commercial. See: http://creativecommons.org/licenses/by-nc/4.0/.

ORCID iD

Maria L Roditis http://orcid.org/0000-0003-2040-024X

\section{REFERENCES}

1 Miech RA, Johnston LD, O'Maley PM. National press release. E-cigarettes surpass tobacco cigarette use among teens. Ann Arbor: University of Michigan News Service, 2014: 16.

2 Cullen KA, Ambrose BK, Gentzke AS, et al. Notes from the Field: Use of Electronic Cigarettes and Any Tobacco Product Among Middle and High School Students United States, 2011-2018. MMWR Morb Mortal Wkly Rep 2018;67:1276-7.

3 Farrelly MC, Duke JC, Nonnemaker J, et al. Association between the real cost media campaign and smoking initiation among youths - United States, 2014-2016. MMWR Morb Mortal Wkly Rep 2017;66:47-50.

4 Farrelly MC, Nonnemaker J, Davis KC, et al. The influence of the National truth campaign on smoking initiation. Am J Prev Med 2009;36:379-84.

5 United Stated Food and Drug Administration, Center for Tobacco Products. The real cost youth tobacco prevention campaign. Available: https://www. fda.gov/TobaccoProducts/PublicHealthEducation/PublicEducationCampaigns/ TheRealCostCampaign/ucm20041242.htm [Accessed 5 Jan 2019].

6 Truth Initiative. Truth Finishlt youth tobacco prevention campaign. Available: httpps:// www.thetruth.com [Accessed 5th Jan 2019].

7 Duke JC, Alexander TN, Zhao X, et al. Youth's awareness of and reactions to the real cost national tobacco public education campaign. PLoS One 2015;10:e0144827.

8 Zhao X, Alexander TN, Hoffman L, et al. Youth receptivity to FDA's the real cost tobacco prevention campaign: evidence from message Pretesting. J Health Commun 2016;21:1153-60.

9 Davis KC, Haviland ML, Messeri P, et al. Evidence of a dose-response relationship between "truth" antismoking ads and youth smoking prevalence. Am J Public Health 2005;95:425-31.

10 US Department of Health and Human Services. The health consequences of smoking - 50 years of progress: a report of the surgeon General. 17. Atlanta, GA: US Department of Health and Human Services, Centers for Disease Control and Prevention, National Center for Chronic Disease Prevention and Health Promotion, Office on Smoking and Health, 2014.

11 Lantz PM, Jacobson PD, Warner KE, et al. Investing in youth tobacco control: a review of smoking prevention and control strategies. Tob Control 2000;9:47-63.

12 Goniewicz ML, Knysak J, Gawron M, et al. Levels of selected carcinogens and toxicants in vapour from electronic cigarettes. Tob Control 2014;23:133-9.
13 Cheng T. Chemical evaluation of electronic cigarettes. Tob Control 2014;23(suppl 2):ii11-17.

14 Barrington-Trimis JL, Samet JM, McConnell R. Flavorings in electronic cigarettes: an unrecognized respiratory health hazard? JAMA 2014;312:2493-4.

15 United Stated Food and Drug Administration. Dr. Scott Gottlieb statements. Available: https://www.fda.gov/NewsEvents/Newsroom/PressAnnouncements/ucm620185.htm [Accessed 5th Jan 2019].

16 England LJ, Bunnell RE, Pechacek TF, et al. Nicotine and the developing human: a neglected element in the electronic cigarette debate. Am J Prev Med 2015:49:286-93.

17 National Academies of Sciences, Engineering, and Medicine (NASEM). Public health consequences of e-cigarettes. Washington, DC: The National Academies Press, 2018

18 Barrington-Trimis JL, Leventhal AM. Adolescents' Use of "Pod Mod" E-Cigarettes Urgent Concerns. N Engl J Med 2018;379:1099-102.

19 Ambrose BK, Day HR, Rostron B, et al. Flavored tobacco product use among US youth aged 12-17 years, 2013-2014. JAMA 2015;314:1871-3.

20 Huang L-L, Baker HM, Meernik C, et al. Impact of non-menthol flavours in tobacco products on perceptions and use among youth, young adults and adults: a systematic review. Tob Control 2017;26:709-19.

21 Harrell MB, Weaver SR, Loukas A, et al. Flavored e-cigarette use: characterizing youth, young adult, and adult users. Prev Med Rep 2017;5:33-40.

22 Shang C, Huang J, Chaloupka FJ, et al. The impact of flavour, device type and warning messages on youth preferences for electronic nicotine delivery systems: evidence from an online discrete choice experiment. Tob Control 2018;27:e152-9.

23 Department of Health and Human Services, Secretary Alex Azar's statements on e-cigarettes. Available: https://www.fda.gov/NewsEvents/Newsroom/ PressAnnouncements/ucm625917.htm [Accessed 5 Jan 2019].

24 Sangalang A, Volinsky AC, Liu J, et al. Identifying potential campaign themes to prevent youth initiation of e-cigarettes. Am J Prev Med 2019;56:S65-75.

25 Cavallo DA, Kong G, Ells DM, et al. Youth generated prevention messages about electronic cigarettes. Health Educ Res 2019;34:247-56.

26 Pierce JP, Choi WS, Gilpin EA, et al. Validation of susceptibility as a predictor of which adolescents take up smoking in the United States. Health Psychol 1996;15:355-61.

27 Braun V, Clarke V, Hayfield N, et al. Thematic analysis. In: Handbook of research methods in health social sciences, 2019: 843-60.

28 Roditis ML, Jones C, Dineva AP, et al. Lessons on addiction messages from "The Real Cost" campaign. Am J Prev Med 2019;56:S24-\$30.

29 Arnett JJ. Optimistic bias in adolescent and adult smokers and nonsmokers. Addict Behav 2000;25:625-32.

30 Popova L, Halpern-Felsher BL. A longitudinal study of adolescents' optimistic bias about risks and benefits of cigarette smoking. Am J Health Behav 2016;40:341-51. 